IJMMS 30:10 (2002) 605-611

PII. S0161171202110349

http://ijmms.hindawi.com

(c) Hindawi Publishing Corp.

\title{
COMMON FIXED POINT THEOREMS FOR A WEAK DISTANCE IN COMPLETE METRIC SPACES
}

\author{
JEONG SHEOK UME and SUCHEOL YI
}

\author{
Received 17 October 2001
}

\begin{abstract}
Using the concept of a $w$-distance, we obtain common fixed point theorems on complete metric spaces. Our results generalize the corresponding theorems of Jungck, Fisher, Dien, and Liu.
\end{abstract}

2000 Mathematics Subject Classification: 47H10.

1. Introduction. In 1976, Caristi [1] proved a fixed point theorem in a complete metric space which generalizes the Banach contraction principle. This theorem is very useful and has many applications. Later, Dien [3] showed that a pair of mappings satisfying both the Banach contraction principle and Caristi's condition in a complete metric space has a common fixed point. That is to say, let $(X, d)$ be a complete metric space and let $S$ and $T$ be two orbitally continuous mappings of $X$ into itself. Suppose that there exists a finite number of functions $\left\{\varphi_{i}\right\}_{1 \leq i \leq N_{0}}$ of $X$ into $\mathbb{R}_{+}$such that

$$
d(S x, T y) \leq q \cdot d(x, y)+\sum_{i=1}^{N_{0}}\left[\varphi_{i}(x)-\varphi_{i}(S x)+\varphi_{i}(y)-\varphi_{i}(T y)\right]
$$

for all $x, y \in X$ and some $q \in[0,1)$. Then $S$ and $T$ have a unique common fixed point $z$ in $X$. Further, if $x \in X$ then $S^{n} x \rightarrow z$ and $T^{n} x \rightarrow z$ as $n \rightarrow \infty$. In particular, if $S$ is an identity mapping, $q=0$, and $N_{0}=1$, then this means a Caristi's fixed point theorem.

Recently, Liu [7] obtained necessary and sufficient conditions for the existence of fixed point of continuous self-mapping by using the ideas of Jungck [5] and Dien [3]: let $f$ be a continuous self-mapping of a metric space $(X, d)$, then $f$ has a fixed point in $X$ if and only if there exist $z \in X$, a mapping $g: X \rightarrow X$, and a function $\Phi$ from $X$ into $[0, \infty)$ such that $f$ and $g$ are compatible, $g(X) \subset f(X), g$ is continuous, and

$$
d(g x, z) \leq r d(f x, z)+[\Phi(f x)-\Phi(g x)]
$$

for all $x \in X$ and some $r \in[0,1)$.

In 1996, Kada et al. [6] introduced the concept of $w$-distance on a metric space as follows: let $X$ be a metric space with metric $d$, then a function $p: X \times X \rightarrow[0, \infty)$ is called a $w$-distance on $X$ if the following are satisfied:

(1) $p(x, z) \leq p(x, y)+p(y, z)$ for any $x, y, z \in X$;

(2) for any $x \in X, p(x, \cdot): X \rightarrow[0, \infty)$ is lower semicontinuous; 
(3) for any $\epsilon>0$, there exists $\delta>0$ such that $p(z, x) \leq \delta$ and $p(z, y) \leq \delta$ imply $d(x, y) \leq \epsilon$.

In this paper, using the concept of a $w$-distance, we obtain common fixed point theorems on complete metric spaces. Our results generalize the corresponding theorems of Jungck [5], Fisher [4], Dien [3], and Liu [7].

2. Definitions and preliminaries. Throughout, we denote by $\mathbb{N}$ the set of positive integers and by $\mathbb{R}_{+}$the set of nonnegative real numbers, that is, $\mathbb{R}_{+}:=[0, \infty)$.

Definition 2.1 (see [3]). A mapping $T$ of a space $X$ into itself is said to be orbitally continuous if $x_{0} \in X$ such that $x_{0}=\lim _{i \rightarrow \infty} T^{n_{i}} x$ for some $x \in X$, then $T x_{0}=$ $\lim _{i \rightarrow \infty} T\left(T^{n_{i}} x\right)$.

Definition 2.2 (see [2]). Let $T$ be a mapping of a metric space $X$ into itself. For each $x \in X$, let

$$
\begin{aligned}
& O(T, x, n)=\left\{x, T x, \ldots, T^{n} x\right\}, \quad n=1,2, \ldots \\
& O(T, x, \infty)=\{x, T x, \ldots\}
\end{aligned}
$$

A space $X$ is said to be $T$-orbitally complete if and only if every Cauchy sequence, which is contained in $O(T, x, \infty)$ for some $x \in X$, converges in $X$.

Definition 2.3 (see [6]). Let $X$ be a metric space with metric $d$. Then a function $p: X \times X \rightarrow \mathbb{R}_{+}$is called a $w$-distance on $X$ if the following properties are satisfied:

(1) $p(x, z) \leq p(x, y)+p(y, z)$ for any $x, y, z \in X$;

(2) for any $x \in X, p(x, \cdot): X \rightarrow \mathbb{R}_{+}$is lower semicontinuous;

(3) for any $\epsilon>0$, there exists $\delta>0$ such that $p(z, x) \leq \delta$ and $p(z, y) \leq \delta$ imply $d(x, y) \leq \epsilon$.

The metric $d$ is a $w$-distance on $X$. Other examples of $w$-distance are stated in [6].

Definition 2.4 (see [5]). Let $(X, d)$ be a metric space and $f, g: X \rightarrow X$. The mappings $f$ and $g$ are called compatible if and only if for every sequence $\left\{x_{n}\right\}_{n \in \mathbb{N}}$ such that $\lim _{n \rightarrow \infty} f x_{n}=\lim _{n \rightarrow \infty} g x_{n}=t$ for some $t \in X$, it implies

$$
\lim _{n \rightarrow \infty} d\left(f g x_{n}, g f x_{n}\right)=0
$$

LEMMA 2.5 (see [6]). Let $X$ be a metric space with metric $d$, and $p$ a $w$-distance on $X$. Let $\left\{x_{n}\right\}$ and $\left\{y_{n}\right\}$ be sequences in $X$, let $\left\{\alpha_{n}\right\}$ and $\left\{\beta_{n}\right\}$ be sequences in $\mathbb{R}_{+}$converging to 0 , and let $x, y, z \in X$. Then the following properties hold:

(i) if $p\left(x_{n}, y\right) \leq \alpha_{n}$ and $p\left(x_{n}, z\right) \leq \beta_{n}$ for any $n \in \mathbb{N}$, then $y=z$. In particular, if $p(x, y)=0$ and $p(x, z)=0$, then $y=z$;

(ii) if $p\left(x_{n}, y_{n}\right) \leq \alpha_{n}$ and $p\left(x_{n}, z\right) \leq \beta_{n}$ for any $n \in \mathbb{N}$, then $\left\{y_{n}\right\}$ converges to $z$;

(iii) if $p\left(x_{n}, x_{m}\right) \leq \alpha_{n}$ for any $n, m \in \mathbb{N}$ with $m>n$, then $\left\{x_{n}\right\}$ is a Cauchy sequence;

(iv) if $p\left(y, x_{n}\right) \leq \alpha_{n}$ for any $n \in \mathbb{N}$, then $\left\{x_{n}\right\}$ is a Cauchy sequence. 


\section{Main results}

THEOREM 3.1. Let $(X, d)$ be a complete metric space with a $w$-distance $p$. Suppose that two mappings $f, g: X \rightarrow X$ and a function $\varphi$ from $X$ into $\mathbb{R}_{+}$are satisfying the following conditions:

(i) $g(X) \subseteq f(X)$,

(ii) there exists $t \in X$ such that $p(t, g x) \leq r \cdot p(t, f x)+[\varphi(f x)-\varphi(g x)]$ for all $x \in X$ and some $r \in[0,1)$,

(iii) for every sequence $\left\{x_{n}\right\}_{n \in \mathbb{N}}$ in $X$ satisfying

$$
\lim _{n \rightarrow \infty} p\left(t, f x_{n}\right)=\lim _{n \rightarrow \infty} p\left(t, g x_{n}\right)=0,
$$

it implies that

$$
\lim _{n \rightarrow \infty} \max \left\{p\left(t, f x_{n}\right), p\left(t, g x_{n}\right), p\left(f g x_{n}, g f x_{n}\right)\right\}=0
$$

(iv) for each $u \in X$ with $u \neq f u$ or $u \neq g u$,

$$
\inf \{p(u, f x)+p(u, g x)+p(f g x, g f x): x \in X\}>0 .
$$

Then $f$ and $g$ have a unique common fixed point in $X$.

Proof. Let $x_{0}$ be a given point of $X$. By (i), there exists $x_{n} \in X$ such that $g x_{n-1}=$ $f x_{n}$ for $n \geq 1$. From Theorem 3.1(ii), we have

$$
p\left(t, f x_{j+1}\right)=p\left(t, g x_{j}\right) \leq r \cdot p\left(t, f x_{j}\right)+\left[\varphi\left(f x_{j}\right)-\varphi\left(g x_{j}\right)\right]
$$

which implies that

$$
\sum_{j=0}^{n-1} p\left(t, f x_{j+1}\right) \leq r \cdot \sum_{j=0}^{n-1} p\left(t, f x_{j}\right)+\sum_{j=0}^{n-1}\left[\varphi\left(f x_{j}\right)-\varphi\left(g x_{j}\right)\right]
$$

that is,

$$
\begin{aligned}
\sum_{j=1}^{n} p\left(t, f x_{j}\right) & \leq \frac{r}{1-r} p\left(t, f x_{0}\right)+\frac{1}{1-r}\left[\varphi\left(f x_{0}\right)-\varphi\left(f x_{n}\right)\right] \\
& \leq \frac{r}{1-r} p\left(t, f x_{0}\right)+\frac{1}{1-r} \varphi\left(f x_{0}\right)
\end{aligned}
$$

which means that the series $\sum_{n=1}^{\infty} p\left(t, f x_{n}\right)$ is convergent, so

$$
\lim _{n \rightarrow \infty} p\left(t, f x_{n}\right)=\lim _{n \rightarrow \infty} p\left(t, g x_{n}\right)=0 .
$$


Suppose that $t \neq f t$ or $t \neq g t$. Then, from Theorem 3.1(iii) and (iv) we obtain that

$$
\begin{aligned}
0 & <\inf \{p(t, f x)+p(t, g x)+p(f g x, g f x): x \in X\} \\
& \leq \inf \left\{p\left(t, f x_{n}\right)+p\left(t, g x_{n}\right)+p\left(f g x_{n}, g f x_{n}\right): n \in \mathbb{N}\right\} \\
& =0 .
\end{aligned}
$$

This is a contradiction. Hence $t$ is a common fixed point of $f$ and $g$.

We prove that $t$ is a unique common fixed point of $f$ and $g$. Let $u$ be a common fixed point of $f$ and $g$. Then, by Theorem 3.1(ii),

$$
\begin{aligned}
& p(t, t)=p(t, g t) \leq r \cdot p(t, f t)+[\varphi(f t)-\varphi(g t)]=r \cdot p(t, t), \\
& p(t, u)=p(t, g u) \leq r \cdot p(t, f u)+[\varphi(f u)-\varphi(g u)]=r \cdot p(t, u) .
\end{aligned}
$$

Thus $p(t, t)=p(t, u)=0$. From Lemma 2.5, we obtain $t=u$. Therefore $t$ is a unique common fixed point of $f$ and $g$.

REMARK 3.2. Theorem 3.1 generalizes and improves Dien [3, Theorem 2.2] and Liu [7, Theorem 3.2].

THEOREM 3.3. Let $f$ be a continuous self-mapping of metric space $(X, d)$. Assume that $f$ has a fixed point in $X$. Then there exists a $w$-distance $p, t \in X$, a continuous mapping $g: X \rightarrow X$, and a function $\varphi$ from $X$ into $\mathbb{R}_{+}$satisfying Theorem 3.1(i), (ii), (iii), and (iv).

Proof. Let $z$ be a fixed point of $f, r=1 / 2, g x=t=z$, and $\varphi(x)=1$ for all $x \in X$. Define $p: X \times X \rightarrow \mathbb{R}_{+}$by

$$
p(x, y)=\max \{d(f x, x), d(f x, y), d(f x, f y)\} \quad \forall x, y \in X .
$$

Suppose that

$$
\lim _{n \rightarrow \infty} p\left(t, f x_{n}\right)=\lim _{n \rightarrow \infty} p\left(t, g x_{n}\right)=0 .
$$

Then it is easy to verify that the results of Theorem 3.3 follow.

THEOREM 3.4. Let $f$ and $g$ be a continuous compatible self-mappings of the metric space $(X, d)$. There exists $t \in X$ satisfying

$$
d(t, g x) \leq r \cdot d(t, f x)+[\varphi(f x)-\varphi(g x)]
$$

for all $x \in X$ and some $r \in[0,1)$. Then

(i) for every sequence $\left\{x_{n}\right\}_{n \in \mathbb{N}}$ in $X$ such that

$$
\lim _{n \rightarrow \infty} d\left(t, f x_{n}\right)=\lim _{n \rightarrow \infty} d\left(t, g x_{n}\right)=0
$$

for some $t \in X$, it implies that

$$
\lim _{n \rightarrow \infty} \max \left\{d\left(t, f x_{n}\right), d\left(t, g x_{n}\right), d\left(f g x_{n}, g f x_{n}\right)\right\}=0
$$


(ii) for each $u \in X$ with $u \neq f u$ or $u \neq g u$,

$$
\inf \{d(u, f x)+d(u, g x)+d(f g x, g f x): x \in X\}>0 .
$$

Proof. The results follow by elementary calculation.

REMARK 3.5. Since the metric $d$ is $w$-distance, from Theorems 3.1, 3.3, and 3.4, we obtain Liu [7, Theorem 3.1].

THEOREM 3.6. Let $(X, d)$ be a complete metric space with a $w$-distance $p$, two mappings $f, g: X \rightarrow X$, and two functions $\varphi, \psi$ from $X$ into $\mathbb{R}_{+}$such that Theorem 3.1(i), (iv) are satisfied,

(i) for every sequence $\left\{x_{n}\right\}_{n \in \mathbb{N}}$ in $X$ such that

$$
\lim _{n \rightarrow \infty} f x_{n}=\lim _{n \rightarrow \infty} g x_{n}=t
$$

for some $t \in X$, it implies that

$$
\lim _{n \rightarrow \infty} \max \left\{p\left(t, f x_{n}\right), p\left(t, g x_{n}\right), p\left(f g x_{n}, g f x_{n}\right)\right\}=0,
$$

(ii)

$$
\begin{aligned}
p(g x, g y) \leq & a_{1} p(f x, f y)+a_{2} p(f x, g x)+a_{3} p(f y, g y) \\
& +a_{4} p(f x, g y)+a_{5}[p(g x, f y) d(f y, g x)]^{1 / 2} \\
& +[\varphi(f x)-\varphi(g x)]+[\psi(f y)-\psi(g y)]
\end{aligned}
$$

for all $x, y \in X$, where $a_{1}, a_{2}, a_{3}, a_{4}$, and $a_{5}$ are in $[0,1)$ with $a_{1}+a_{4}+a_{5}<1$ and $a_{1}+a_{2}+a_{3}+2 a_{4}<1$.

Then $f$ and $g$ have a unique common fixed point in $X$.

Proof. Let $x_{0}$ be an arbitrary point of $X$. By Theorem 3.1(i), we obtain a sequence $\left\{x_{n}\right\}$ in $X$ such that $g x_{n-1}=f x_{n}$ for $n \geq 1$. Let $\gamma_{n}=p\left(f x_{n}, f x_{n+1}\right)$ for $n \geq 0$. It follows from Theorem 3.6(ii) that

$$
\begin{aligned}
\gamma_{j+1}= & p\left(g x_{j}, g x_{j+1}\right) \\
\leq & a_{1} p\left(f x_{j}, f x_{j+1}\right)+a_{2} p\left(f x_{j}, g x_{j}\right)+a_{3} p\left(f x_{j+1}, g x_{j+1}\right) \\
& +a_{4} p\left(f x_{j}, g x_{j+1}\right)+a_{5}\left[p\left(g x_{j}, f x_{j+1}\right) d\left(f x_{j+1}, g x_{j}\right)\right]^{1 / 2} \\
& +\left[\varphi\left(f x_{j}\right)-\varphi\left(g x_{j}\right)\right]+\left[\psi\left(f x_{j+1}\right)-\psi\left(g x_{j+1}\right)\right] \\
\leq & \left(a_{1}+a_{2}+a_{4}\right) \gamma_{j}+\left(a_{3}+a_{4}\right) \gamma_{j+1} \\
& +\left[\varphi\left(f x_{j}\right)-\varphi\left(f x_{j+1}\right)\right]+\left[\psi\left(f x_{j+1}\right)-\psi\left(f x_{j+2}\right)\right],
\end{aligned}
$$

which implies that

$$
\gamma_{j+1} \leq L_{1} \gamma_{j}+L_{2}\left[\varphi\left(f x_{j}\right)-\varphi\left(f x_{j+1}\right)+\psi\left(f x_{j+1}\right)-\psi\left(f x_{j+2}\right)\right]
$$

where

$$
L_{1}=\frac{a_{1}+a_{2}+a_{4}}{1-a_{3}-a_{4}}, \quad L_{2}=\frac{1}{1-a_{3}-a_{4}} .
$$


Thus

$$
\sum_{j=1}^{n} \gamma_{j} \leq \frac{L_{1}}{1-L_{1}} \gamma_{0}+\frac{L_{2}}{1-L_{1}}\left[\varphi\left(f x_{0}\right)+\psi\left(f x_{1}\right)\right]
$$

for all $n \geq 1$. Hence, the series $\sum_{n=1}^{\infty} \gamma_{n}$ is convergent. For any $n, r \geq 1$, we have

$$
p\left(f x_{n}, f x_{n+r}\right) \leq \sum_{i=n}^{n+r-1} \gamma_{i} .
$$

By Lemma 2.5, this implies that $\left\{f x_{n}\right\}_{n=1}^{\infty}$ is a Cauchy sequence in $X$. Since $X$ is a complete metric space, there exists $t \in X$ such that $f x_{n} \rightarrow t$ as $n \rightarrow \infty$. From Theorem 3.6(i), we have

$$
\lim _{n \rightarrow \infty} \max \left\{p\left(t, f x_{n}\right), p\left(t, g x_{n}\right), p\left(f g x_{n}, g f x_{n}\right)\right\}=0 .
$$

Suppose that $t \neq f t$ or $t \neq g t$, then from Theorem 3.1(iv) we obtain that

$$
\begin{aligned}
0 & <\inf \{p(t, f x)+p(t, g x)+p(f g x, g f x): x \in X\} \\
& \leq \inf \left\{p\left(t, f x_{n}\right)+p\left(t, g x_{n}\right)+p\left(f g x_{n}, g f x_{n}\right): n \in \mathbb{N}\right\} \\
& =0 .
\end{aligned}
$$

which is a contradiction. Therefore $t$ is a common fixed point of $f$ and $g$. It follows from Lemma 2.5 and Theorem 3.6(ii) that $t$ is a unique common fixed point of $f$ and $g$.

THEOREM 3.7. Let $f$ be a continuous self-mapping of a metric space $(X, d)$. Assume that $f$ has a fixed point in $X$. Then there exist a $w$-distance $p, t \in X$, a continuous mapping $g: X \rightarrow X$, and functions $\varphi, \psi$ from $X$ into $\mathbb{R}_{+}$satisfying Theorem 3.1(i), (iv) and Theorem 3.6(i), (ii).

Proof. By a method similar to that in the proof of Theorem 3.3, the results follow.

REMARK 3.8. Since the metric $d$ is $w$-distance, from Theorems 3.4, 3.6, and 3.7, we obtain Jungck [5, Theorem], Fisher [4, Theorem 2], and Liu [7, Theorem 3.3].

ACKNOWLEDGMent. This work was supported by Korea Research Foundation Grant (KRF-2001-015-DP0025).

\section{REFERENCES}

[1] J. Caristi, Fixed point theorems for mappings satisfying inwardness conditions, Trans. Amer. Math. Soc. 215 (1976), 241-251.

[2] L. B. Ćirić, A generalization of Banach's contraction principle, Proc. Amer. Math. Soc. 45 (1974), 267-273.

[3] N. H. Dien, Some remarks on common fixed point theorems, J. Math. Anal. Appl. 187 (1994), no. 1, 76-90.

[4] B. Fisher, Mappings with a common fixed point, Math. Sem. Notes Kobe Univ. 7 (1979), no. 1, 81-84. 
[5] G. Jungck, Commuting mappings and fixed points, Amer. Math. Monthly 83 (1976), no. 4, 261-263.

[6] O. Kada, T. Suzuki, and W. Takahashi, Nonconvex minimization theorems and fixed point theorems in complete metric spaces, Math. Japon. 44 (1996), no. 2, 381-391.

[7] Z. Liu, Y. Xu, and Y. J. Cho, On characterizations of fixed and common fixed points, J. Math. Anal. Appl. 222 (1998), no. 2, 494-504.

Jeong Sheok Ume: Department of Applied Mathematics, Changwon National UniverSITY, CHANGWON 641-773, KOREA

E-mail address: jsume@sarim.changwon.ac.kr

Sucheol Yi: Department of Applied Mathematics, Changwon National University, CHANGWON 641-773, KoreA

E-mail address: scyi@sarim.changwon.ac.kr 


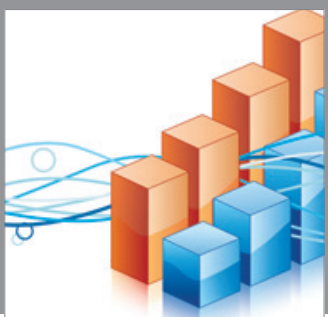

Advances in

Operations Research

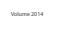

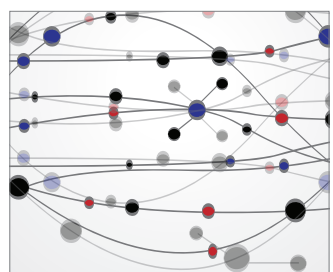

\section{The Scientific} World Journal
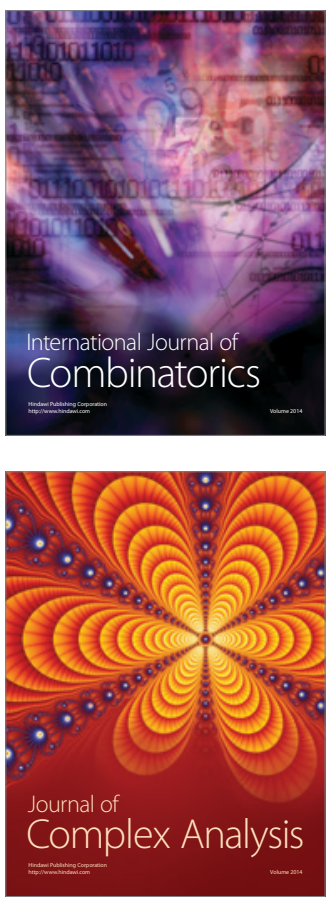

International Journal of

Mathematics and

Mathematical

Sciences
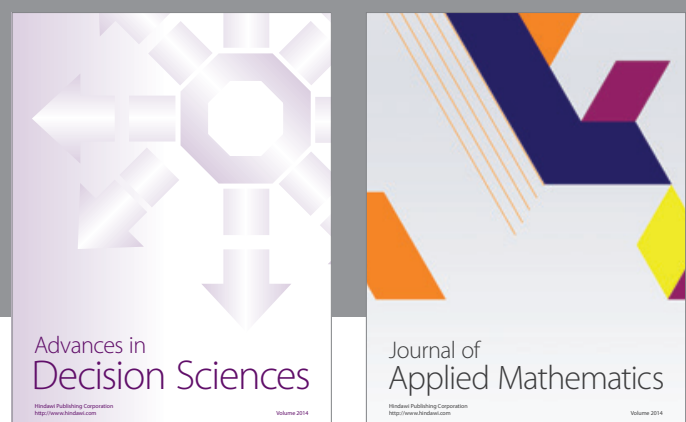

Journal of

Applied Mathematics
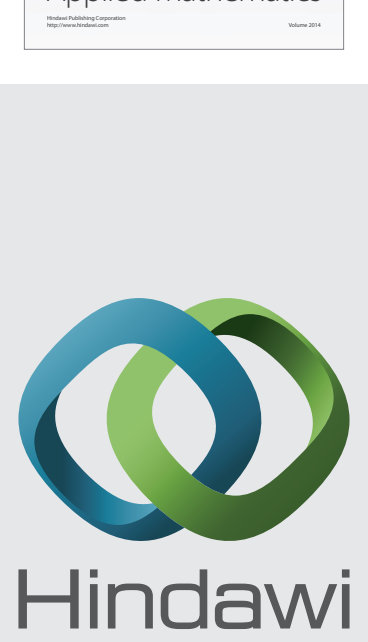

Submit your manuscripts at http://www.hindawi.com
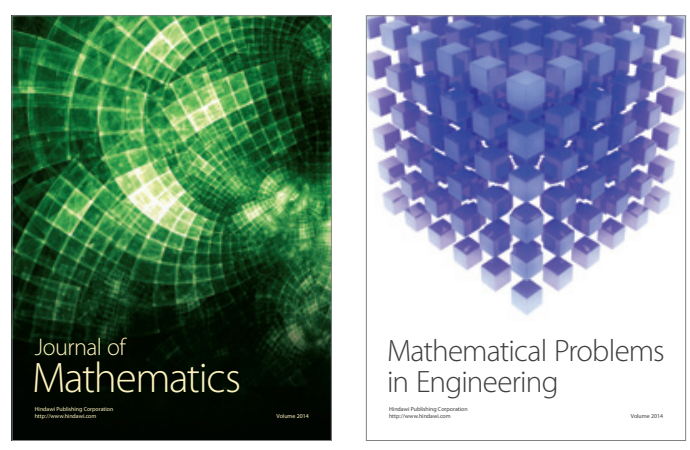

Mathematical Problems in Engineering
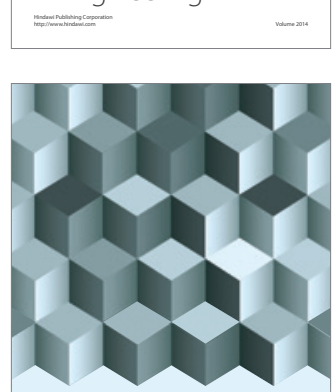

Journal of

Function Spaces
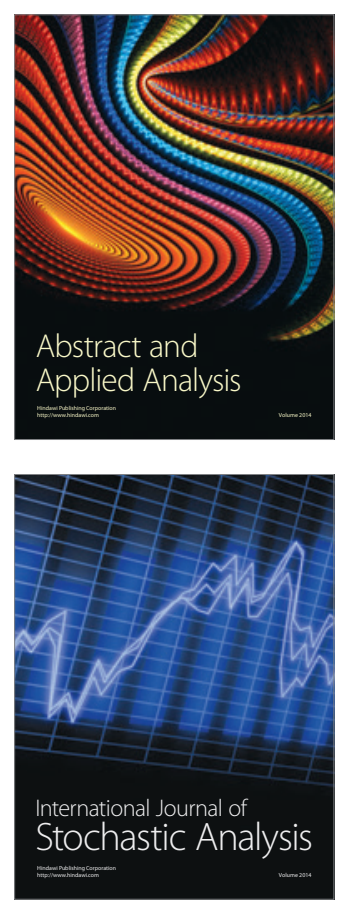

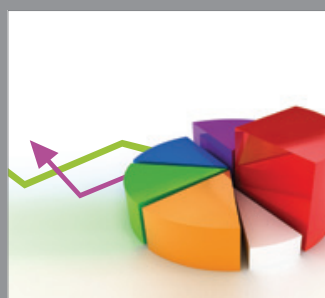

ournal of

Probability and Statistics

Promensencen
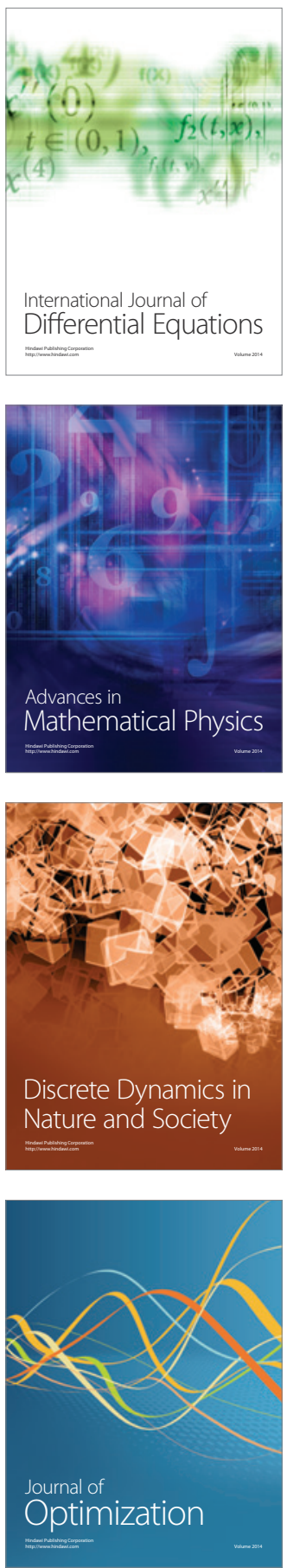